\title{
Small size resectoscope in isthmocele repair: case
} report

\begin{abstract}
The presence of a uterine cesarean scar defect (CSD) is usually asymptomatic or relates to postmenstrual spotting and dark red or brown discharge, pelvic pain or infertility. Since hysteroscopic isthmoplasty has been documented to be minimally invasive and effective for symptomatic relief, we prefer channel-like resectoscopic treatment for symptomatic CDS with small size resectoscope. 16-Fr resectoscope allows us to perform standard maneuvers of resectoscopic CSD repair according to the anatomy of cervical canal with the advantages of miniaturized instrumentation. In the present case report asymptomatic patient underwent hysteroscopic isthmoplasty after shared decision-making and medical treatment have been evaluated.
\end{abstract}

Keywords: Caesarean scar defect, Isthmocele, Hysteroscopic resection, Miniresectoscope
Volume 7 Issue 5 - 2017

\author{
Giampietro Gubbini,' Paolo Casadio,, ${ }^{2}$ Mario \\ Franchini ${ }^{3}$ \\ 'Madre Fortunata Toniolo Clinic, Italy \\ ${ }^{2}$ University of Bologna, Italy \\ ${ }^{3}$ Tuscany Health Agency, Italy
}

Correspondence: Mario Franchini, Regional Health Agency of Tuscany, Borgo Santa Croce 17, 50 I22, Florence, Italy, Tel 39 3292268330; 39-055243209, Email framagi@alice.it

Received: February 19, 2017 | Published: August II, 2017

\section{Introduction}

Cesarean scar defect (CSD), niche, or isthmocele is commonly detected as an incidental finding on transvaginal ultrasound (TVS) as a wedge-shape anechoic area at the site of previous cesarean section (CS), ${ }^{1}$ The presence of a uterine scar defect is usually asymptomatic or relates to postmenstrual spotting and dark red or brown discharge, pelvic pain or infertility. ${ }^{2}$

Multiple techniques have been used for CSD treatment: reconstructive therapies including laparoscopic or robot-assisted laparoscopic excision, vaginal repair and channel-like resectoscopic treatment. ${ }^{3-6}$ All these procedures excise or ablate the fibrotic tissue of niche, suggesting that the removal of the local inflamed tissue may contribute to the improvement of symptoms. Since the aim of CSD repair in women with symptoms is to facilitate the drainage of menstrual blood through the cervix, the hysteroscopic approach, flattening the CSD and restoring the continuity of the cervical canal area, results to be effective and less invasive comparing to laparoscopic excision and vaginal repair.?

\section{Case report}

A 39-year-old woman with a history of 2 previous cesarean delivery complained about/of persistent postmenstrual spotting, brown discharge and pelvic pain for the past 18 months with no improvement in symptomatology during 6-month oral contraceptive treatment. During transvaginal ultrasound an anechoic area was detected with $>2.2 \mathrm{~mm}$ thickness of the myometrium over the defect and hysteroscopic evaluation confirmed the presence of a niche (Figure 1).

A channel-like hysteroscopic treatment with $16 \mathrm{Fr}$ resectoscope (Gubbini system, Tontarra, Medizintechnik, GmbH, Germany) was planned immediately at the end of menstrual period. Before beginning the procedure, the bladder was filled with methylene blue solution to enable early identification of bladder injuries. With vaginoscopic approach the isthmocele was localized and a bipolar loop was used to resect the fibrotic tissue of the proximal (step 1) and distal (step 2) part of the niche with 360-degrre resection (endocervical ablation) of the all residual cervical canal inflamed tissue surrounding the diverticulum.
The entire niche surface was superficially coagulated with a roller ball electrode (step 3) in order to replace it with mono stratified cubic cell-type epithelium. The procedure was ended controlling eventual endocervical vessel bleeding by reducing inflow and pressure of the distending medium (step 4) (Figure $2 \& 3$ ).

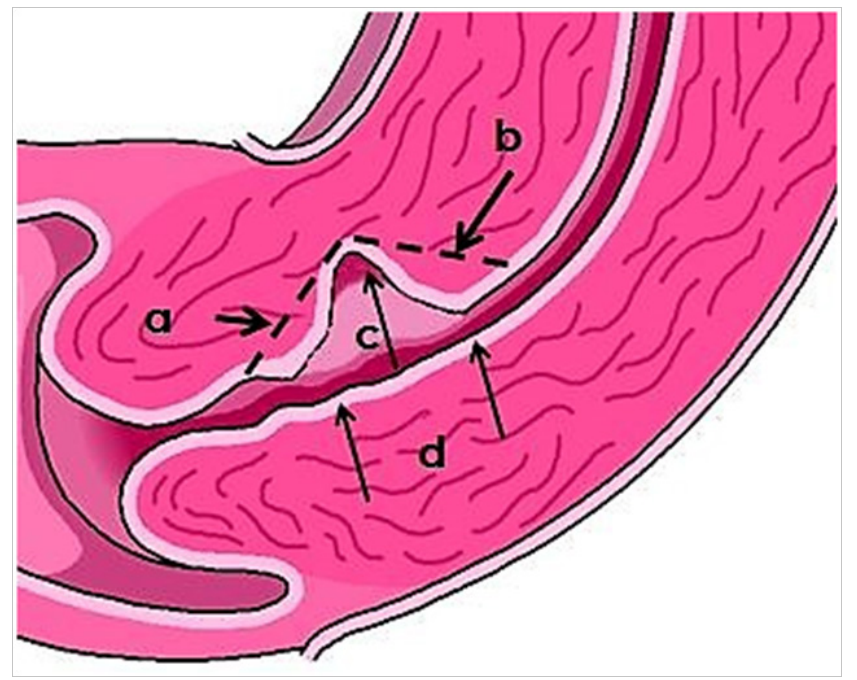

Figure I Channel-like resectoscopic treatment of CSD. (a) Resection of the fibrotic tissue of the proximal part. (b) Resection of the fibrotic tissue of the distal part. (c) Coagulation of niche surface with a rollerball electrode. (d) 360-degree "endocervical ablation" surrounding the diverticulum.

The patient became free from symptoms immediately after surgery and at 6-month hysteroscopic follow up a small size niche was still present and covered with thin and smooth epithelium (Figure 4).

\section{Discussion}

Several hypotheses may explain CSD development: a very low incision through the cervical tissue, impaired wound healing, adhesion formation, inadequate suturing or incomplete closure of the uterine scar due to endometrial closure technique. ${ }^{8} \mathrm{~A}$ recent meta-analysis reported a similar incidence of CSD in women who received singlelayer closure $(25.5 \%$ vs $43.0 \%$; RR $0.77,95 \%$ CI 0.36 to $1.64 ; 5$ trials; 
350 participants; low quality of evidence) compared to women who received double-layer closure. ${ }^{9}$
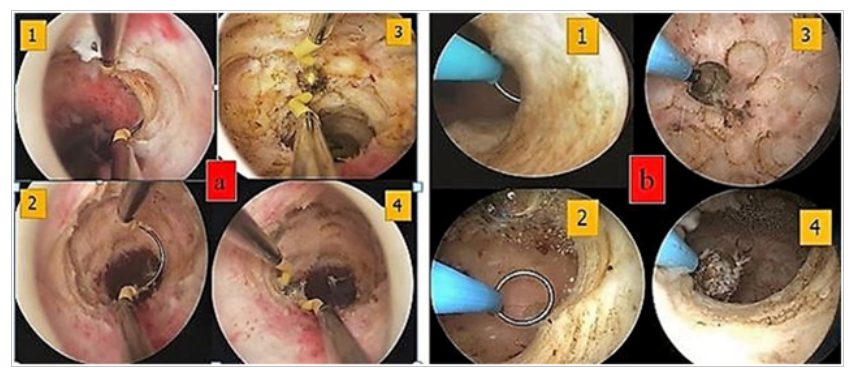

Figure 2 Surgical technique for channel-like resectoscopic treatment. (a) 26 Fr resectoscope and (b) $16 \mathrm{Fr}$ resectoscope. (I-2) resection of the fibrotic tissue of the distal and proximal part of the niche. (3) Coagulation of the entire niche surface superficially with a rollerball electrode. (4) 360-degree "endocervical ablation" of the all-residual cervical canal inflamed tissue surrounding the diverticulum. I6 Fr resectoscope allows to perform standard maneuvers of resectoscopic CSD repair with the advantages of miniaturized instrumentation and without the complications related to cervical dilation.

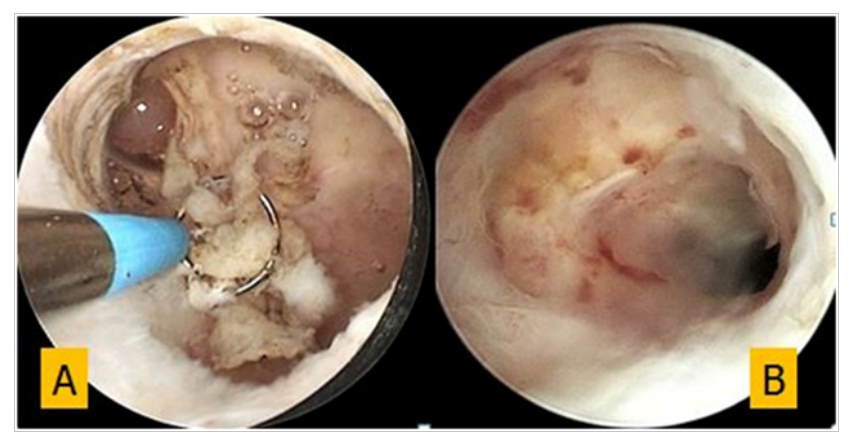

Figure 3 Hysteroscopic CSD appearance (A) during resection of fibrotic tissue and (B) after 6-month follow up.

The proposed mechanism of postmenstrual spotting and pelvic pain related to CSDs is a blood accumulation in the pouch, impair drainage and in situ production from new small vessels. The degree of this symptom may be related to the size of the defect. Larger defects trap more blood and are more likely to lead to prolonged postmenstrual spotting. ${ }^{2,10}$

Hysteroscopic isthmoplasty flattening the CSD area, restores the continuity of the cervical canal and improves menstrual drainage reducing blood accumulation in the niche and reflux into the uterine cavity. The hysteroscopic repair is performed, with small variations among authors, by resecting only the inferior/distal rim of the niche or with superior/proximal edge of the defectusing a $26 \mathrm{Fr}$ or $27 \mathrm{Fr}$ resectoscope. The procedure is ended with or without superficial coagulation of vessels in the niche surface with the aim at reducing blood loss from these fragile vessels. ${ }^{10-12}$

We perform isthmoplasty, using a $16 \mathrm{Fr}$ resectoscope with vaginoscopic approach and resect the fibrotic tissue of the distal and proximal part of the niche as well as all residual cervical canal inflamed tissue surrounding the diverticulum(360-degree "endocervical ablation") in order to replace it with mono stratified cubic cell-type epithelium. The mini resectoscope allows us to perform standard maneuvers of resectoscopic CSD repair according to the anatomy with the advantages of miniaturized instrumentation and without the complications related to cervical dilation. ${ }^{13}$

It is important to emphasize that not all CSD cause symptoms or infertility, and as the treatment is predominantly performed to relieve symptoms isthmocele without symptoms should not be treated. Since CSD treatment is to improve menstrual drainage rather than to increase the myometrial thickness, in symptomatic women a cut off of 2 to $3 \mathrm{~mm}$ of the overlying myometrium has not been suggested for vaginal or laparoscopic repair with a multiple-layer closure. ${ }^{14}$

A similar improvement in uterine bleeding in $59 \%$ to $100 \%$ of cases were detected after laparoscopic or vaginal approach and channel like repair. ${ }^{15}$

Although, the hysteroscopic repair could be associated with a risk of uterine perforation and bladder injury nevertheless, complications result to be lower than by vaginal or laparoscopic approach. ${ }^{16}$ Moreover, the hysteroscopic CSD repair time is considerably reduced 11-23 minutes $^{13}$ when compared to laparoscopic $42-117$ minutes, ${ }^{14,17}$ robotic 240 minutes $^{5}$ or vaginal approach $33-120$ minutes. ${ }^{18,19}$

\section{Conclusion}

In conclusion, we prefer to treat symptomatic CDS with small size resectoscope because hysteroscopic isthmoplasty has been documented to be minimally invasive and effective for symptomatic relief after shared decision-making and medical treatment have been evaluated with patient.

\section{Acknowledgements}

None.

\section{Conflicts of interest}

None.

\section{Disclosure statement}

The author Giampietro Gubbini is the inventor of "Gubbini system" no royalties. The authors Paolo Casadio e Mario Franchini have nothing to disclose.

\section{References}

1. Tulandi T, Cohen A. Emerging Manifestations of Cesarean Scar Defect in Reproductive-aged Women. J Minim Invasive Gynecol. 2016;23(6):893-902.

2. Tower AM, Frishman GN. Cesarean Scar Defects: An Under recognized Cause of Abnormal Uterine Bleeding and Other Gynecologic Complications. J Minim Invasive Gynecol. 2013;20(5):562-572.

3. Florio P, Filippeschi M, Moncini I, et al. Hysteroscopic treatment of the cesarean-induced isthmocele in restoring infertility. Curr Opin Obstet Gynecol. 2012;24(3):180-186.

4. Donnez O, Donnez J, Orellana R, et al. Gynecological and obstetrical outcomes after laparoscopic repair of a cesarean scar defect in a series of 38 women. Fertil Steril. 2017;107(1):289-296.

5. Yalcinkaya TM, Akar ME, Kammire LD, et al. Robotic-assisted laparoscopic repair of symptomatic cesarean scar defect: a report of two cases. J Reprod Med. 2011;56(5-6):265-270.

6. Luo L, Niu G, Wang Q Xie HZ, et al. Vaginal repair of cesarean section scar diverticula. J Minim Invasive Gynecol. 2012;19(4):454-458.

7. van derVoet LF, Vervoort AJ, Veersema S, et al. Minimally invasive therapy for gynaecological symptoms related to a niche in the caesarean scar: a systematic review. BJOG. 2014;121(2):145-156.

8. Vervoort AJ, Uittenbogaard LB, Hehenkamp WJ, et al. Why do niches develop in Caesarean uterine scars? Hypotheses on the aetiology of niche development. Hum Reprod. 2015;30(12):2695-2702. 
9. Di SpiezioSardo A, Saccone G, McCurdy R, et al. Risk of cesarean scar defect in single- versus double-layer uterine closure: a systematic review and meta-analysis of randomized controlled trials. Ultrasound Obstet Gynecol. 2017.

10. Fabres C, Arriagada P, Fernandez C, et al. Surgical treatment and followup of women with intermenstrual bleeding due to cesarean section scar defect. J Minim Invasive Gynecol. 2005;12(1):25-28.

11. Gubbini G, Casadio P, Marra E. Resectoscopic correction of the "isthmocele" in women with postmenstrual abnormal uterine bleeding and secondary infertility. J Minim Invasive Gynecol. 2008;15(2):172175.

12. Raimondo G, Grifone G, Raimondo D, et al. Hysteroscopic treatment of symptomatic cesarean induced isthmocele: a prospective study. J Minim Invasive Gynecol. 2015;22(2):297-301.

13. Gubbini G, Centini G, Nascetti D Marra E, et al. Surgical hysteroscopic treatment of cesarean-induced isthmocele in restoring fertility: prospective study. J Minim Invasive Gynecol. 2011;18(2):234-237.

14. Api M, Boza A, Gorgen H, Api O. Should cesarean scar defect be treated laparoscopically? A case report and review of the literature. J Minim Invasive Gynecol. 2015;22(7):1145-1152.
15. Chang Y, Tsai EM, Long CY, et al. Resectoscopic treatment combined with sono hysterographic evaluation of women with postmenstrual bleeding as a result of previous cesarean delivery. Am J Obstet Gynecol. 2016;200(4):370.e1-370.e4

16. Tsuji S, Murakami T, Kimura F, et al. Management of secondary infertility following cesarean section: Report from the Subcommittee of the Reproductive Endocrinology Committee of the Japan Society of Obstetrics and Gynecology. J Obstet Gynaecol Res. 2015;41(9):13051312 .

17. Li C, Guo Y, Liu Y, Cheng J,et al. Hysteroscopic and laparoscopic management of uterine defects on previous cesarean delivery scars. $J$ Perinat Med. 2014;42(3):363-370.

18. Zhou J, Yao M, Wang H Tan W, et al. Vaginal Repair of Cesarean Section Scar Diverticula that Resulted in Improved Postoperative Menstruation. J Minim Invasive Gynecol. 2016;23(6):969-978.

19. Chen H, Yao M, Tao J, et al. Surgery experience in transvaginal cesarean section diverticulum (CSD) repair. Gynecol Minim Invas Ther. 2016;5:148-151 